\title{
SIMULATION OF FIELD SPECTROMETER DATA FOR REMOTE SENSING MEASUREMENTS TO RETRIEVE CHOLOROPHYLL $a$ IN CASE 2 WATER
}

\author{
Md. Monirul ISLAM ${ }^{1}$, Kimiteru SADO $^{2}$ and Yoshiaki MIYATA ${ }^{3}$ \\ ${ }^{1}$ Member of JSCE, Dr. of Eng., JSPS Fellow, Dept. of Civil Engineering, Kitami Institute of Technology (165 Koen-cho, \\ Kitami 090-8507, Japan) \\ ${ }^{2}$ Fellow of JSCE, Dr. of Eng., Professor, Dept. of Civil Engineering, Kitami Institute of Technology (165 Koen-cho, \\ Kitami 090-8507, Japan) \\ ${ }^{3}$ Member of JSCE, M. Eng., Chief Engineer, Hokkaido Engineering Office, Environmental Investigation and Technology \\ Institute Co., (7F of RICH7-7 Bld., Kita-7 Nishi 7, 1-30 Kita-ku, Sapporo, 060-0807, Japan)
}

\begin{abstract}
This paper describe about technique to retrieve chlorophyll $a$ concentration by using field spectroradiometer data with fluorometer data and the Sea-viewing Wide Field-of-view Sensor (SeaWiFS) data. Spectroradiometer data were coupled with fluorometer data to find out the best suited bands ratio to monitor the chlorophyll $a$ concentration for inland water. Remote sensing reflectance measurements were used to evaluate the performance of several default ocean color chlorophyll algorithms for SeaWiFS data. Using the default chlorophyll algorithms used in TeraScan System (OC2-V2) and SeaDAS (OC4-V4) as the basis of comparison; this study examined the validity of these empirical chlorophyll algorithms with in situ data. Remote sensing reflectance data from spectroradiometer and in situ chlorophyll $a$ data from fluorometer were collected for Lake Abashiri, and SeaWiFS data for Lake Saroma were used. It is shown that the chlorophyll $a$ concentration from fluorometer and reflectance from spectroradiometer lies in exploiting the signal provided by the chlorophyll $a$ red absorption peak near $670 \mathrm{~nm}$. Two-band ratio based on a ratio of reflectance 670 and $700 \mathrm{~nm}$ provided a good correlation for a linear model, compared with blue-green two band ratio.
\end{abstract}

Key Words: Inland water, SeaWiFS, spectroradiometer data, chlorophyll a, remote sensing reflectance, turbidity, water transparency

\section{INTRODUCTION}

There has been considerable success in optical remote sensing of chlorophyll $a$ in case 1 water where the variation of optical properties is dominated by phytoplankton and associated material, and some consensus are emerging with regard to appropriate algorithms. In contrast, chlorophyll $a$ retrieval in case 2 waters, where the optical properties of inorganic suspended matter and colored dissolved organic matter (CDOM) must also be considered, is still a matter of intense research activity, and a few convincing example are available of satellite-derived chlorophyll $a$ concentrations for such water (Ruddic et al 2001). However, the demand for detail monitoring of chlorophyll $a$ concentration in case 2 water is very high because of the need to manage the inland and coastal eutropication and because of the importance of estuarine and coastal phytoplankton for atmospheric carbon dioxide and hence possible climate change.

Stream ecosystems around the world are being impacted by the eutrophication. The eutrophication is the state of having high nutrient content and high organic production ${ }^{1)}$. Most water quality models simulate the increase in eutrophication based on initial condition of the water body, therefore, demand comprehensive water quality sampling programs. However, the conventional measurement of water quality requires in situ sampling and expensive and time-consuming laboratory work. Due to these limitations, the sample size often cannot be large enough to cover the entire water body. Therefore, the difficulty of synoptic and successive water quality sampling becomes a barrier to water quality monitoring and forecasting. Remote sensing could overcome these constraints by providing an alternative means of water quality monitoring over a range of temporal and spatial scale. Therefore, imagery from satellite and aircraft remote sensing system have been used in the assessment of water quality parameters such as temperature, chlorophyll $a$, turbidity, and total suspended solids for lakes, reservoirs and coastal waters $^{2), 3), 4)}$.

In this study, SeaWiFS data was used to view and check the validity of the algorithms for inland water chlorophyll $a$ concentration in Lake Saroma, 
Hokkaido, Japan. Spectroradiometer and fluorometer data were collected for Lake Abashiri, Hokkaido, Japan. These data sets were also used to check the validity of the derived chlorophyll algorithms by using the same band ratio of SeaWiFS, and finally organized the data sets to find out the correlation between spectral index and chlorophyll $a$ concentration.

\section{STUDY AREA}

The study sites are Abashiri and Saroma Lakes, located in Hokkaido, Japan. Lake Saroma is the third largest Lake in Japan and the largest in Hokkaido. Both Lakes are famous for tourist resorts and Saroma Lake has the largest haul of scallop culture in Japan. But some times water blooms have occurred in both Lakes. Nowadays lakes' waters are contaminated by river waters that come with contaminated matters from the sewage and farmland. Therefore, the water quality monitoring is very important for these lakes.

\section{DATA COLLECTION AND PREPARATION}

Fluorometer data for in situ measurements and spectroradiometer data were collected from 1997 to 2000 in Lake Abashiri. Initially the data was sorted for good quality for spectral data, based on the spectral quality for radiation measurements. The spectroradiometer data set ranges from 350 to $900 \mathrm{~nm}$ by resolution of $1 \mathrm{~nm}$. The spectroradiometer data set was accompanied by fluorometer data for chlorophyll $a$, turbidity, temperature in different water depths, and Secchi disk data. Water transparencies were measured by using Secchi disk depth. The averaged chlorophyll $a$ concentration and turbidity were estimated for $0 \sim 1 \mathrm{~m}, 0 \sim 2 \mathrm{~m}$ and $0 \sim$ transparency depth. The other data set of received SeaWiFS imagery for Lake Saroma and the ground truth chlorophyll $a$ data observed by Saroma Fishery Cooperative Association in different stations for the same date of imagery were collected.

\section{(1) Spectral radiation data collection}

The spectral radiation data were collected from the period of 1997 to 2000; downward spectral irradiance (solar radiation, $\mathrm{H}$ in Figure 1) and upward water surface spectral radiance (U in Figure 1). The water surface reflectance data represent the ratio of reflected energy to incident energy with values ranging from 0 to 1 . The upward water surface radiance is composed of two components; the direct reflected radiation at water surface and the scattered radiation from transferred light under water surface which possess water quality information. Solar radiation was measured by upward radiance from diffusible whiteboard.

\section{(2) Fluorometer data}

Chlorophyll $a$, turbidity, water temperature in different depths was collected by using fluorometer sensor. These chlorophyll $a$ data were used as in situ measurements of chlorophyll $a$ concentration.

\section{(3) Transparency data}

Well timed ground truth in the form of Secchi disk measurements were used to estimate the Lake transparency of Lake Abashiri. Secchi disk data were collected from the end of 1998 to 2000 . These transparency data were correlated with turbidity data. From this regression line the transparency for remaining data were estimated.

\section{(4) SeaWiFS imagery}

SeaWiFS data has been received at Kitami Institute of Technology, Kitami, Hokkaido, Japan. Data set has been processed by using TeraScan system from SeaWiFS 10 bit data to level 1b. Only the required portion corresponding to the area of interest was extracted from the full scene. After that the swcolor2 (OC2-v2) algorithm was used to estimate the chlorophyll $a$ concentration. In TeraScan system swcolor and swcolor 2 algorithms are used for case 1 water and case 2 water, respectively. Therefore, we can estimate chlorophyll $a$ concentration from SeaWiFS data in our laboratory by using the facilities of TeraScan system.

\section{METHODOLOGY}

\section{(1) Estimation of remote sensing reflectance from spectroradiometer}

We used spectroradiometer to measure upward radiance and downward irradiance. Through the components of light absorption and scattering coefficients, the water body controls the ratio between light scattering and absorption values, and thus determines the subsurface reflectance and in turn the emergent flux that will be sensed by radiometers ${ }^{5)}$. Because the medium composition affects the absorption and scattering coefficients differently at various wavelengths, the resulting spectral distribution can be mathematically modeled and/or measured by a spectroradiometer from above and under the water's surface, and thus can be used to provide information about the water quality. The measuring system is shown in Figure $1 . \mathbf{H}\left(\mu \mathrm{w} \mathrm{cm}^{-2}\right.$ $\left.n m^{-1}\right)$ and $\mathbf{U}\left(\mu w \mathrm{~cm}^{-2} s r^{-1} \mathrm{~nm}^{-1}\right)$ represent the spectral irradiance (downward) and spectral radiance (upward). Solar radiation can be measured 
by knowing amount of $\mathbf{H}$, while reflection constituents from water surface and under water surface can be measured by knowing the amount of $\mathbf{U}$. But it is very difficult to measure solar radiation directly therefore the, upward radiation from the diffusible whiteboard is measured for solar radiation which can be considered equal to solar radiation due to the reflectance 1 to all direction. So we measured reflected energy $\mathbf{W}\left(\mu w \mathrm{~cm}^{-2} \mathrm{sr}^{-1} \mathrm{~nm}^{-1}\right)$ from diffusible whiteboard by using spectroradiometer for measuring solar energy. Reflectance $\left(\boldsymbol{R}_{r}\right)$ for any particular wavelength can be estimated by

$$
\begin{aligned}
& R_{r}=\frac{\pi U}{H} \\
& H=\pi W\left(\mu w \mathrm{~cm}^{-2} \mathrm{~nm}^{-1}\right)
\end{aligned}
$$

Therefore, remote sensing reflectance can be calculated by

$$
R_{r s}=\frac{U}{H \cos \theta_{0}}\left(s r^{-1}\right)
$$

where, $\theta_{0}$ is solar zenith angle.

\section{(2) Chlorophyll a concentration estimated by SeaWiFS data}

In TeraScan system OC2-V2 algorithm is used for case 2 water to estimate the chlorophyll $a$ concentration. But NASA has published the new version, OC4-V4. The fundamental equations of OC2-V2 and OC4-V4 algorithms are as follows:

$$
\begin{aligned}
& \text { Chl } a=10^{\left(a 0+a 1^{*} R+a 2^{*} R^{2}+a 3^{*} R^{3}\right)}+a 4 \\
& R=\log \left\{R_{r s}(490) / R_{r s}(555)\right\} \\
& a=[0.2974,-2.2429,0.08358-0.0077,-0.0929
\end{aligned}
$$

$$
\begin{aligned}
& \text { Chla }=10^{\left(a 0+a 1^{*} R+a 2^{*} R^{2}+a 3^{*} R^{3}+a 4^{*} R^{4}\right)} \\
& R=\log \left\{\max \left[R_{r s}(443), R_{r s}(490), R_{r s}(510)\right] / R_{r s}(555)\right\} \\
& a=[0.366,-3.067,1.93,0.649,-1.532]
\end{aligned}
$$

where, $R_{r s}(443), R_{r s}(490), R_{r s}(510)$ and $R_{r s}(555)$ are remote sensing reflectance for SeaWiFS band center $443,490,510$, and $555 \mathrm{~nm}$ with band width $20 \mathrm{~mm}$, respectively. And $\boldsymbol{R}$ is the logarithmic value of remote sensing reflectance ratio for two selective bands. We have estimated chlorophyll $a$ concentration for Lake Saroma by using acquired SeaWiFS images and compared the results with in situ data. In situ chlorophyll $a$ concentrations were collected from five stations (st-2 to st-6) for 6 June 2002 in Lake Saroma. Some remote sensing estimated chlorophyll $a$ were not appeared with in situ measured locations, therefore in situ measurements and remote sensing estimation were interpolated using linear interpolation technique to

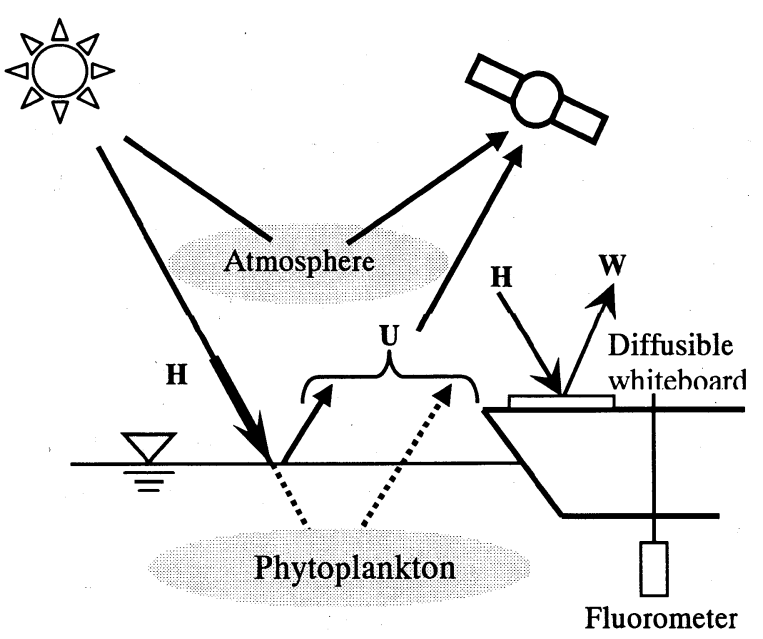

Fig. 1 Measurements of water surface reflectance and fluorometer data

incorporate in situ data with remote sensing estimation. The comparison between in situ measurements with OC2-V2 estimation is shown in Figure 2. Figure 3 shows the comparisons among in situ with OC2-V2 and OC4-V4 algorithms for four measurements stations with tabular form. The analyses are based on interpolated estimated remote sensing data with the interpolated in situ measurements surrounding the five stations. Due to insufficient of in situ measurements and the small number of remote sensing measurement's pixels, spatial interpolation was performed. Interpolated results of chlorophyll $a$ concentration may vary with actual measurements, but the trend of variations of chlorophyll $a$ concentration can be understood from this results. The variation for OC2-V2 and OC4-V4 are nearly same and show lower values compared with in situ though OC4-V4 shows little bit higher estimating values than that of $\mathrm{OC} 2-\mathrm{V} 2$.

\section{(3) Assimilation of spectroradiometer data to compare with SeaWiFS data}

Fluorometer and spectroradiometer data were

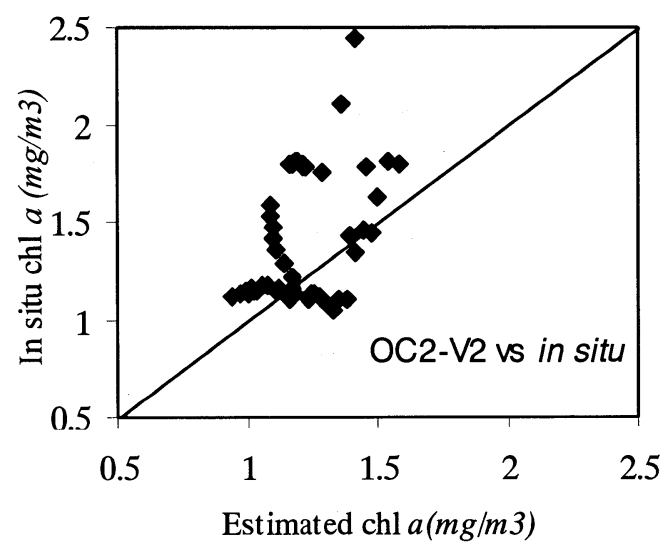

Fig. 2 Scattered plots for OC2-V2 estimated chlorophyll $a$ concentration and in situ measurements in Lake Saroma, 6 June 2002 
collected for the year of 1997, 1998, 1999 and 2000 for Lake Abashiri in different stations. The fluorometer data of chlorophyll $a$ were considered as ground truth data. These data were accompanied by turbidity, salinity and water temperature data. In this study we used only turbidity and chlorophyll data. Spectroradiometer wavelength ranges from 350 to $900 \mathrm{~nm}$. Therefore, we prepared the spectral data corresponding to the wavelength of 443, 490, 510 and $555 \mathrm{~nm}$ to assimilate with SeaWiFS data. Remote sensing reflectances can be estimated by using equation 3 . But for the logarithmic value for the ratio of remote sensing reflectance $(\boldsymbol{R})$ for two selective bands were estimated by

$$
\begin{aligned}
& R=\log \left[\frac{R_{r s}(\lambda 1)}{R_{r s}(\lambda 2)}\right] \\
& =\log \left[\frac{\frac{U(\lambda 1)}{\pi W(\lambda 1) \cos \theta}}{\frac{U(\lambda 2)}{\pi W(\lambda 2) \cos \theta}}\right]=\log \left[\frac{U(\lambda 1)}{U(\lambda 2)} \frac{W(\lambda 2)}{W(\lambda 1)}\right]
\end{aligned}
$$

Therefore, this equation becomes independent from solar zenith angle. By using equation 4, 5 and 6 we have estimated chlorophyll $a$ for spectroradiometer reflectance which was assimilated according to SeaWiFS bands. Therefore, the measurements of chlorophyll $a$ from spectroradiometer reflectance assimilate the chlorophyll $a$ from SeaWiFS data. The comparisons among chlorophyll $a$ estimated from spectral value of spectroradiometer and measured by fluorometer are shown in Figure 4. The ground truths data shows higher values compared with estimated results. Although OC4-V4 shows a little bit higher estimation compared with $\mathrm{OC} 2-\mathrm{V} 2$, it does not contribute significant development for case 2 water. Therefore, another estimation technique should be necessary to estimate the chlorophyll $a$

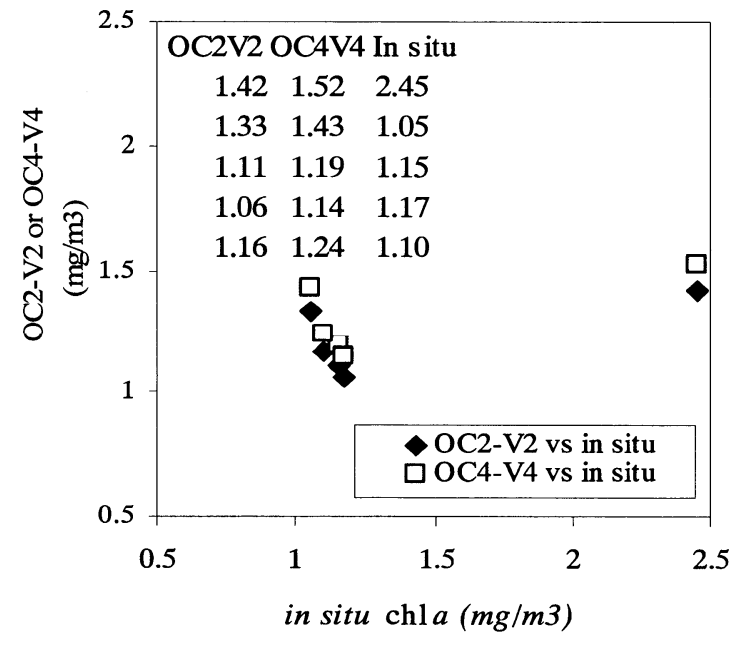

Fig. 3 Scattered plots for remote sensing estimated chlorophyll $a$ concentration and in situ measurements in Lake Saroma, 6 June 2002 concentration for highly turbid inland and coastal water.

The largest source of error for chlorophyll $a$ retrieval in case 2 waters are generally attributed to the bio-optical model that relates water leaving radiance or reflectance to the chlorophyll $a$ concentration and to treatment of aerosol reflectance in the atmospheric correction procedure ${ }^{6}$. Latter one was only considered in OC2-V2 and OC4-V4 algorithms. Considering only blue to green, two band ratios were used in these algorithms.

\section{(4) Selection of band wavelength for chlorophyll $a$ concentration measurements}

Many empirical models, with varying degrees of complexity, have been proposed within the last two decades to relate the backscattering properties observed to the concentration of dissolved substances in the water column. These models may use information in single or multiple bands, and employ different functional forms like the power function, multiple regression hyperbolic, secondorder and third-order polynomials, or most commonly the log-transformation ${ }^{7}$. Normally, most of algorithms were developed for case 1 water by using blue-green two band ratio. Blue-green two band ratio algorithms are popular for case 1 waters, which may not be appropriated for case 2 water.

Both field and laboratory spectrometric measurements of reflectance and absorption are essential to developing semi-empirical and analytical (radiative transfer) models that can describe the interactions of light and in-water materials ${ }^{8)}$. In our study we have used field spectrometric measurements. Field spectra of both the material(s) of interest and other materials present in the environment can be used to address such issues as what spatial and spectral resolutions are required for detection. Some field measured

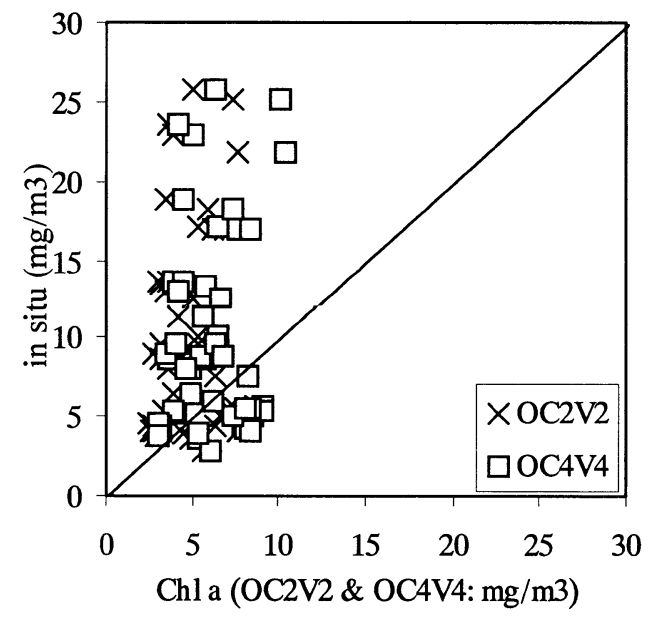

Fig. 4. Comparison among the estimated chlorophyll $a$ concentration with in situ data in Lake Abashiri, 1997-2000 


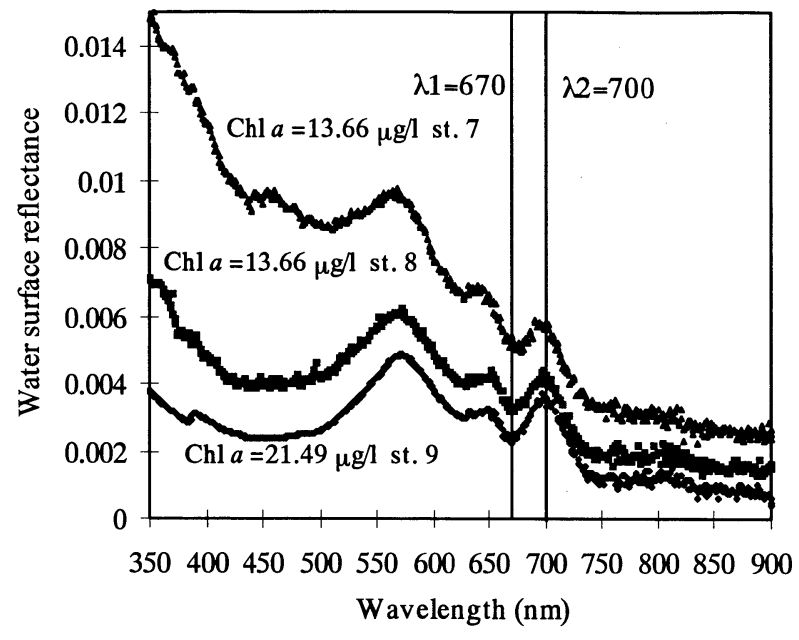

Fig. 5 Reflectance spectra measured at water surface for known chlorophyll $a$ concentration average from 0 to $2 \mathrm{~m}$ in Lake Abashiri, 21 August 1997

spectral reflectances at water surface for the absorption of different concentration chlorophyll $a$ in Lake Abashiri are shown in Figure 5.

Chlorophyll $a$ is a phytopigment present in all algae groups in inland waters and shows absorption bands in the blue wavelength at $440 \mathrm{~nm}$ and in the red wavelength at near $670 \mathrm{~nm}$ (Figure 5), leaving a maximum green reflectance at $570 \mathrm{~nm}$ due to an electron excitation process. But the band near $670 \mathrm{~nm}$ shows the distinct absorption for this case. The red edge ascent near $700 \mathrm{~nm}$ that is narrowed to a peak by growing water absorption in the near infrared is also correlated to increasing chlorophyll $a$ contents.

At $400-500 \mathrm{~nm}$ spectral range the absorption from tripton (particulate matter after removal of phytoplankton pigments) is generally greater than phytoplankton absorption, and the total particulate absorption coefficients shows an exponentially decreasing form for the $400-570 \mathrm{~nm}$ range, typical of tripton (detrital) absorption ${ }^{6}$. Considering that a satellite-based sensor sees only the effect of the total absorption coefficients (particulate plus dissolved matter plus pure water), it is clearly important to be

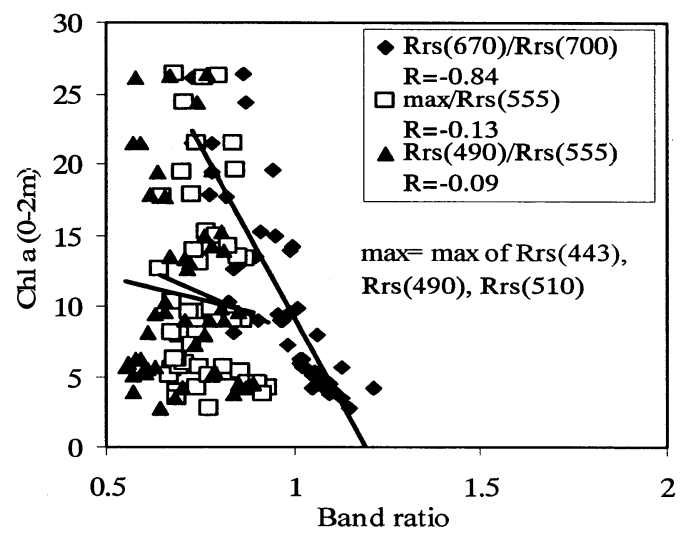

Fig. 6 Correlation of chlorophyll $a$ concentration with two band ratio in Lake Abashiri, 1997-2000

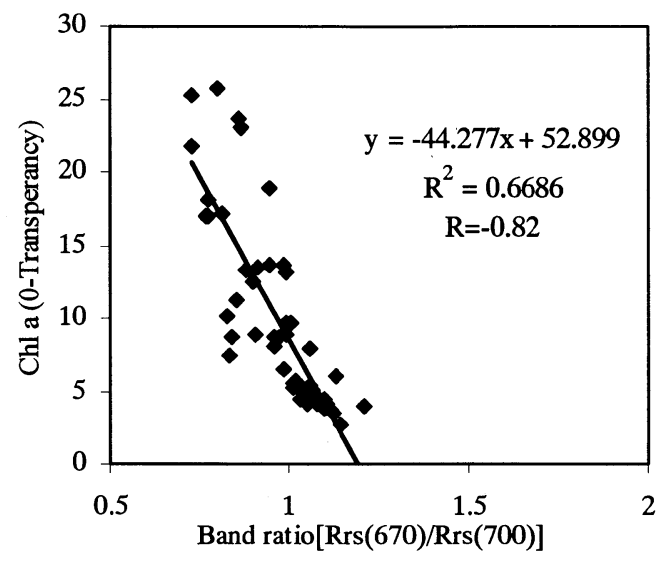

(a) Chlorophyll $a$ average from 0 to transparency

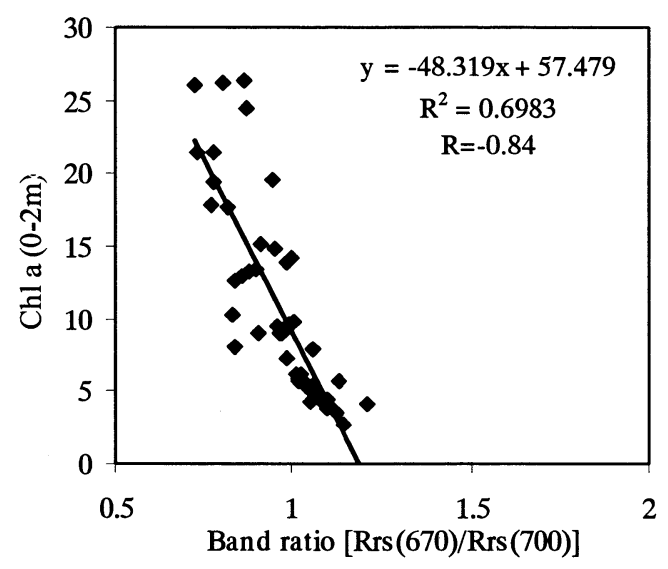

(b) Chlorophyll $a$ average from 0 to 2 meter

Fig. 7 Correlation of observed averaged (0-2m) chlorophyll $a$ with spectral band ratio (670/700) in Lake Abashiri, 1997-2000

able to distinguish phytoplankton-related features at least in the total particulate absorption spectrum. Study shows that satellite-derived total absorption coefficient divided into components arising from phytoplankton and other material will clearly be difficult without use of the 670-700nm chlorophyll $a$ absorption features, where the absorption of phytoplankton is nearly equal to the total particulates ${ }^{6}$. Normally the band ratios used in phytoplankton retrieval algorithms have a good correlation for case 1 water ${ }^{9}$.

Therefore, we examined spectral bands ratio against the measured chlorophyll $a$ that is shown in Figure 6. Bands ratio 670/700 shows good correlation compared with other bands ratios those were used in OC2-V2 and OC4-V4 algorithms.

\section{(5) Correlation for a model to retrieve chlorophyll $a$}

Based on the correlation with the in situ data, one of the most important relationships observed in this study was the relationship between spectral bands ratio and the average of chlorophyll a concentration from water surface to the depth up to the water transparency. Water transparency was 
measured by using Secchi disk depth. The transparency (Secchi disk depth) is negatively correlated with turbidity $(\mathrm{R}=-0.64)$. We have calculated the average of chlorophyll $a$ concentration from 0 to $1 \mathrm{~m}, 0$ to the depth of water transparency and 0 to $2 \mathrm{~m}$ depth. The correlation between the band ratio (670/700) and chlorophyll $a$ concentration average from 0 to the depth of transparency, and average from 0 to $2 \mathrm{~m}$ depth, are shown in Figure 7(a) and 7(b). The average value for chlorophyll $a$ from 0 to the depth of transparency shows the correlation coefficients $\mathrm{R}=-$ 0.82 for the band ratio $(670 / 700)$, while correlation coefficient $R=-0.84$ is shown for the average value from 0 to $2 \mathrm{~m}$ depth. But the average value of chlorophyll a concentration from 0 to $1 \mathrm{~m}$ shows the correlation coefficient $\mathrm{R}=-0.82$ with band ration $(670 / 700)$. The average transparency of Lake Abashiri is $1.60 \mathrm{~m}$. Therefore, there is not significant difference between the correlations with chlorophyll $a$ average value obtained for the depth to transparency and $2 \mathrm{~m}$, though the average value from 0 to $2 \mathrm{~m}$ shows comparatively better correlation. We have also tested the correlation for the band ratio (700/670), inverse of above mentioned band ratio (670/700), which shows the very similar correlation with positive value $\mathrm{R}=0.82$ and $\mathrm{R}=0.84$ for the average value of chlorophyll from 0 to depth of transparency and 0 to $2 \mathrm{~m}$, respectively. Hence, chlorophyll $a$, obtained average 0 to $2 \mathrm{~m}$ depth, was appeared to correlate better with band ratio $(670 / 700)$.

\section{RESULTS AND DISCUSSIONS}

Sigmoid form of the OC.2-V2 and OC4-V4 algorithms are very sensitive to small variations of $\operatorname{Rrs}(490) / \operatorname{Rrs}(555)$ or $\max [\operatorname{Rrs}(443), \quad \operatorname{Rrs}(490)$, $\operatorname{Rrs}(510)] / \operatorname{Rrs}(555), \quad$ and then estimate unrealistically high or low chlorophyll $a$ in cases of high gelbstoff, detrital and/or accessory pigment absorption. These two algorithms show high estimation for lower ranges and low estimation for higher range of chlorophyll $a$ concentrations in case of Lake Saroma and Abashiri. Therefore, it is concluded that blue-green two band ratio algorithm does not show good adaptations for case 2 water, though which is popular for case 1 water.

Chlorophyll $a$ is a phytopigment present in all algae groups in Lake Abashiri shows distinct absorption bands in the red wavelength near at $670 \mathrm{~nm}$ (Figure 5), leaving a maximum green reflectance. The red edge ascent near $700 \mathrm{~nm}$ that is narrowed to a peak by growing water absorption in the near infrared is also correlated to increasing chlorophyll $a$. Based on the correlation with in situ data, the ratio of band 670 and $700 \mathrm{~nm}$ wavelength produced a good correlation $(\mathrm{R}=-0.84)$ with chlorophyll $a$ concentration average from 0 to $2 \mathrm{~m}$ depth. Using this linear model, a chlorophyll $a$ distribution map can be produced for Lake Abashiri and similarly another linear model can be produced for Lake Saroma.

Therefore, hand-held spectroradiometer data have been used successfully to assimilate the spectral band to the remote sensing technique for the estimation of chlorophyll $a$ concentration for case 2 water in Lake Abashiri. This study suggests that blue-green two band ratio could not be used for the monitoring of chlorophyll $a$ in case 2 water. The ratio of bands wavelength ranges from 670 to 700 would be better to monitor the chlorophyll $a$ for inland and high turbid water.

ACKNOWLEDGEMENT: The authors gratefully acknowledge Japan Society for Promotion of Science (JSPS) providing the fellowship and Grant-in-Aid to first author.

\section{REFERENCES}

1) Wetzel, R. G: Death, detritus and energy-flow in aquatic ecosystem. Freshwater Biology, 33, 83-89, 1995.

2) Lillesand, T. M., Johnson, W. L., Deuell, R. L. Lindstrom, O. M. and Meisner, D. E: Use of Landsat data to predict the trophic state of Minnesota Lakes. Photogrammetric Engineering \& Remote Sensing, 49(2), 219-229, 1983.

3) Lathrop, R. G. and Lillesand, T. M: Monitoring water quality and river plume transport in Green Bay, Lake Michigan with SPOT-1 imagery. Photogrammetric Engineering \& Remote Sensing, 55(3), 349-354, 1989.

4) Ruiz-Azuara, P: Multitemporal analysis of "simulation" Landsat imagery (MSS and TM) for monitoring primary production in a small tropical coastal lagoon, Photogrammetric Engineering \& Remote Sensing, 61(2), 877-898, 1995.

5) Jupp, D. L. B, Kirk, J. T. O and Haris,G. P: Detection, identification and mapping of cyanobacteria: Using remote sensing to measure the optical water quality of turbid inland water, Aust. J. Mar. Freshwater Res., 45, 801-828, 1994.

6) Ruddick, K. G., Gons, J. G., Rijkeboer, M., and Tilstone, G: Optical remote sensing of chlorophyll $a$ in case 2 waters by using of an adaptive two band algorithm with optical error properties, J. Appl. Opt. 40(21), 3575-3585, 2001.

7) Fireston, E. R., and Hooker, S. B: SeaWiFS prelaunch technical report series final cumulative index, NASA Tech. Memo., TM-1998-104566, 43, 4-8, 1998.

8) Dekker, A. G: Operational tools for remote sensing of water quality: A prototype tool kit. Vrije Universiteit, Amsterdam Institute for Environmental Studies. BCRS Report 96-18, ISBN 9054112158.

9) Tassan, S. Local algorithms using SeaWiFS data for the retrieval of phytoplankton, pigments, suspended sediment, and yellow substance in coastal water, Applied Optics, 33(12), 2369-2377, 1994. 